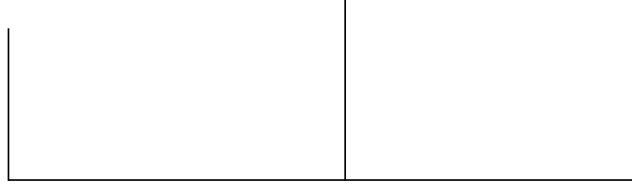

Rev. Latinoam. Psicopat. Fund., III, 4, 180-185

“Is diminished Responsability Relevant?”

Brian Boettcher

Journal of Forensic Psychiatry On-Line, March 27, 1999.

Resenhado por: Olimpia Maluf Souza

\title{
A diminuição de responsabilidade é relevante?
}

O artigo de Brian Boettcher - "Is diminished Responsability Relevant?” -, como sugere o próprio título, questiona a relevância atual da diminuição da responsabilidade penal, bem como se tais jurisdições aboliram as defesas menos ásperas e exageradas. O termo diminished responsability (nos E.U.A. - diminished capacity) é utilizado para designar todo o apelo legal de diminuição do débito para homicídios não premeditados, permitindo ao juiz mais coerência nas sentenças. Para muitos, a diminuição da responsabilidade implica tomar o crime do ponto de vista racional-emotivo, o que esbarraria na dificuldade de determinar o nível de intencionalidade do assassino. Moore, em Act and Crime, discute a conexão entre volição e ato, isto é, se a vontade é a fonte essencial da ação, se ela é um estado ativo da mente ou se ela é um estado mental passageiro. Enfim, a questão é verificar se há uma conexão entre o objeto da vontade e a mente. O que Moore indica são os vários meios de se olhar para essas conexões e a intenção. Contudo, os argumentos contra essa volição são fortes e a pergunta sobre sua existência de fato ainda não está satisfatoriamente respondida. $\mathrm{O}$ requisito para se determinar o Reus de Actus na lei criminal é um ato complexo, pois a fronteira com o Rea de Mens é nebulosa, em virtude da conexão íntima e necessária entre ambos. Também existe o fato de que o Reus de Actus tem seu próprio elemento mental, ou seja, é preciso que haja desejo ou a vontade necessária para cometer a ofensa. A intenção no Rea de Mens é uma espécie de von- 
tade que se difere por haver mais divisões dentro dela. Há, também, a questão dessa intenção não ser decorrente de objetos simples, mas de objetos complexos de algum status criminal. Por outro lado, a negligência é uma área problemática, pois causa "sofrimento" tanto aos teóricos quanto à lei, na qual é classificada como um elemento defeituoso, de falta. A questão prática importante é a de como o juiz e o júri vêem um caso particular com base em aspectos de caráter essencialmente subjetivos. A lei toma o Rea de Mens no seu significado técnico e refere-se a ele como sendo qualquer estado mental que é requerido pela ofensa. Há uma tensão natural entre a teoria e a prática e somente às vezes a teoria parece concordar com a prática. Tal aspecto abre espaço para que o discurso social tome parte sobre o que está legislado, influenciando o seu desenvolvimento. Esse estado promove um debate superficial sobre o que filosoficamente caracteriza-se como ato. Essa dificuldade conceitual torna-se polêmica principalmente quando um caso particular de assassinato é reduzido à qualidade de homicídio não premeditado. Para ilustrar tal dificuldade, o autor recorre a um caso ocorrido na Austrália, cujo protagonista é por ele denominado de Senhor A. Aos 27 anos, esse referido senhor filho de mãe alcoólatra e deprimida assassinou seu padrasto. Afirma que fora abusado sexualmente pelo padrasto quando criança e descreve-o como sendo pessoa possuidora de características compatíveis com a pedofilia, homossexualismo e sadismo. Já havia tentado o suicídio por três vezes, sendo internado em Hospital Psiquiátrico após a última tentativa.

Foi atribuído a ele um quadro compatível com "Desordem de personalidade borderline” (sintomas depressivos, auto-estima baixa, empobrecimento da auto-imagem, relacionamentos interpessoais estáveis, impulsividade e autodestruição, instabilidade na afeição, sentimentos crônicos de vazio, sentimentos paranóicos e sintomas de dissociação parcial ou total com a realidade). Seu psiquiatra alegou que Sr. A sofria, por ocasião do assassinato, de duas condições psiquiátricas significativas: "Desordem de personalidade borderline” e "Desordem psicótica induzida” pelo uso de anfetaminas. O uso de anfetaminas pode gerar enganos e alucinações que podem perdurar de um mês ou mais após a suspensão do medicamento. Assim, somou-se às revoltas acumuladas contra o pai adotivo, um estado de confusão mental, que prejudicou sua capacidade de julgamento e tornou dificultada a capacidade de decidir sobre o certo e o errado. Embora um caráter crônico de depressão e de comportamento suicida tivesse ocorrido anteriormente, era necessário considerar as complicações e seqüelas da suspensão do uso de anfetaminas como causa possível de agravamento do quadro depressivo. Esse estado de depressão influenciou a corte de forma a que tomasse o seu julgamento compatível com diminuição da responsabilidade, pois o assassinato do pai adotivo foi considerado como decorrente da impossibilidade de se controlar mediante às provocações do mesmo, associado ao quadro depressivo. Em síntese, a corte ponderou os efeitos da anfe- 
tamina no organismo como parte responsável pela incapacidade de controle físico e mental do Sr. A. Assim sendo, ele foi considerado culpado de homicídio não premeditado, o que implicou a consideração da diminuição da sua responsabilidade por ocasião do cometimento do crime. O autor considera a ponderação de três psiquiatras experimentados em psiquiatria forense e as alegações do juiz para demonstrar o quanto o quadro mental associado a uma depressão por supressão de anfetamina serviu de argumento para cada um deles, no sentido de argumentarem na direção de uma diminuição da responsabilidade. O juiz afirmou que o prisioneiro vivia um “inferno urbano", que o júri levasse em conta o seu estado de dissociação quando assassinou o pai adotivo. Dessa forma, ponderou não só a questão da diminuição da responsabilidade como justificou a ação como motivada pelas constantes provocações do pai adotivo a que Sr. A estava sujeito. A aceitação desses dois argumentos envolve um alto grau de subjetividade, pois implica um julgamento de valor. Os psiquiatras e psicólogo da prisão alertaram sobre o comportamento suicida do prisioneiro, mas tal medida não impediu que o mesmo se matasse após seu julgamento, quando foi transferido para a prisão rural.

Esse caso desencadeia algumas dúvidas: pode ter ocorrido alguma indução na decisão do júri após as ponderações do juiz? Qual a força de uma imprensa sensacionalista? A solução para essas questões na Austrália se deu por meio da decisão de acabar com o julgamento da diminuição da responsabilidade. Assim, ao júri e ao juiz cabe o julgamento do crime em si. O problema é que a sociedade australiana acredita que o indivíduo que mata com intenção deve carregar a etiqueta de assassino para o resto da sua vida. São intransigentes com esse tipo de assassino e vigiam tanto o uso da etiqueta como a ação do júri.

Outra sugestão aventada foi a de suprimir totalmente a defesa por diminuição da responsabilidade. Dessa forma, o estado mental seria transferido para o Rea de Mens e para a intenção. Essa medida, no entanto, geraria um amplo debate com a psiquiatria, uma vez que a intenção clara e definida não elimina por completo um quadro significativo de loucura. Assim, são as razões que estão por trás das intenções que são as questões importantes para alegar a diminuição da responsabilidade. Em alguns estados americanos, o conceito de diminuição da responsabilidade foi abolido, ou seja, insanidade e competência não são reconhecidas como componentes de culpa ou inocência. As avaliações psiquiátricas só são ouvidas em depoimentos oficiais quando a competência do réu é questionável. Se ele for considerado incompetente para assumir a responsabilidade do ato (crime), sua remoção para tratamento em Hospitais Estaduais é imediatamente providenciada. Tanto psiquiatras quanto juízes e promotores admitem que essa medida flexibiliza o dispositivo legal. No entanto, o autor alerta que a eliminação da desordem de personalidade dos julgamentos favorece as manobras de advogados, bem como caracteriza um retrocesso, pois abre possibilidades para as influências de classe, racismo etc. Tal 
medida abre ainda possibilidade para as negociações secretas, uma vez tratar-se de acordos que ocorrem longe dos olhos da sociedade. O comitê de revisão de lei discute, portanto, a necessidade de permanência da diminuição da responsabilidade. Assim, houve sugestões para que a compreensão do que venha a ser insanidade do ponto de vista legal deva ser alargada, pois há diferentes graus de insanidade e, portanto, de comprometimento da responsabilidade. Na Austrália do Sul separa-se o elemento mental dos elementos objetivos. Dessa forma, a legislação local prevê como dano mental (deterioração mental): senilidade, incapacidade intelectual, doença mental e desordem severa de personalidade; e como cobertura para o que prevê como incompetência mental, se ao tempo do cometimento do delito o acusado estava sofrendo de um dano mental que o levou a: 1) não saber nem a natureza e nem a qualidade da sua conduta; 2) não conseguir discernir sua conduta como errada; 3) não era capaz de controlar sua conduta.

Um dos problemas atuais importantes sobre a questão da diminuição da responsabilidade está na terminologia adotada tanto por psiquiatras quanto pela legislação. Outro problema refere-se a alguns tipos de desordens psiquiátricas leves que podem estar presentes em qualquer pessoa sem que seu autocontrole seja afetado, tais desordens não devem ser consideradas em crimes tão sérios. Alerta, no entanto, para a existência de alguns tipos de desordens que tornam seus portadores extremamente perigosos - psicopatias sexuais. Há, contudo, uma evidência que está vindo à luz, que é a de que existe de fato uma diferença organicamente reconhecível nos lóbulos frontais desse tipo de psicopata. Essas diferenças podem ser detectadas por meio de exames especializados e essa modalidade de psicopatia merece atenção especial da lei.

A questão de manter ou retirar a desordem de personalidade da defesa é uma direção argumentativa legal que o autor defende, mas reconhece que esses procedimentos estão ainda em fase de estudo. Até que tais discussões cheguem a um consenso, o autor sugere uma forma de linguagem mais apropriada para melhor conceituar essas categorias, estabelecendo o que deve ser considerado como desordem, tanto temporária quanto crônica, mas que afeta a capacidade de julgamento, a cognição e reduz substancialmente a responsabilidade. Se o júri verificar tais condições, o débito deve ser o de atribuição de homicídio não premeditado. No entanto, até que mudanças ocorram na lei, os psiquiatras, os advogados e o júri devem fazer de tudo para reparar as deficiências do sistema. 
"The psychiatric perspectives of epilepsy" Joseph M. Scwartz,M.D. and Laura Marsh, M.D.

Psychosomatics, 41, p. 31-38, Feb/2000, Resenhado por: Annelise Urbanavicius Costanti Lara

\section{As perspectivas psiquiátricas da epilepsia}

Este artigo, publicado no Psycosomatics de fevereiro de 2000, apresenta um método de abordagem clínica das condições psiquiátricas que ocorrem nos pacientes epiléticos, iniciando uma série de artigos a respeito da neuropsiquiatria.

Os autores propõem que se observe cada paciente com epilepsia por meio de quatro perspectivas: 1) da doença; 2) “dimensional”; 3) comportamental; e 4) da história de vida, com o enfoque no período interictal.

A perspectiva da "doença” assume que a causa do sintoma psiquiátrico seria a própria disfunção biológica, envolvendo o sistema nervoso, ou seja, o cérebro seria o substrato para as síndromes psiquiátricas. Os exemplos são a depressão maior e a síndrome do pânico, que são mais prevalentes na população de epiléticos do que na população geral.

A perspectiva “dimensional” é baseada nas características humanas que variam individualmente ao longo do tempo, que seriam parâmetros psiquiátricos equivalentes ao peso e à pressão arterial para a medicina física. As dimensões mais importantes seriam o temperamento (ou personalidade) e a inteligência. Segundo os autores, embora os pacientes com epilepsia não sejam mais propensos à problemas emocionais ligados ao temperamento do que membros da população geral, a epilepsia expõe as vulnerabilidades do temperamento, especialmente em indivíduos situados em "extremos" de personalidade. São discutidos também os fatores significativos em relação ao déficit cognitivo e intelectual aos quais os epilépticos estão expostos.

A perspectiva "comportamental" é relativa aos comportamentos motivados ou não, mal adaptativos, com destaque para a agressividade e o comportamento anormal em relação à doença (como, por exemplo, as pseudoconvulsões).

A perspectiva da "história de vida" envolve conhecer o paciente como pessoa, compreendendo as dificuldades de vida decorrentes tanto da epilepsia (como desmoralização, estigma, dificuldades de relacionamento social, problemas no tra- 
balho) quanto dos efeitos adversos ou conseqüentes do uso da medicação anti-epiléptica.

Apresenta-se o método descrito para se planejar um tratamento que envolva estes quatro aspectos, e os exemplos citados no artigo procuram demonstrar sua utilidade no estudo dos aspectos psiquiátricos dos pacientes com epilepsia.

A importância desta discussão reside no alerta que se faz para que não se procure entender um sintoma psiquiátrico baseado em uma única perspectiva, que pode estar sendo mal aplicada a um problema que poderia ser "melhor visto através de outras lentes”, conforme concluem os autores. 